\title{
Jahrestagung 1994
}

Die Jahrestagung der Vereinigung fand 1994 erstmals nach der Wiedervereinigung Deutschlands in einem der neuen Bundesländer statt. Tagungsort war vom 5. bis 8. Oktober Halle/Saale. Die Vereinigung war in Halle schon einmal, im Jahre 1931, gewesen. Damals war es die achte, dieses Mal die 72. Tagung der Vereinigung seit ihrer Gründung 1922 und die 54. Tagung (einschließlich der Berliner Sondertagung 1990) seit ihrer Wiederbegründung im Jahre 1949.

Den Vorsitz führte Walter Schmitt Glaeser, die Aussprachen leiteten die Vorstandsmitglieder Hans-Peter Schneider (1. Beratungsgegenstand) und Karl Korinek (2. Beratungsgegenstand). Die Organisation vor Ort hatte Michael Kilian als kooptiertes Vorstandsmitglied übernommen. $\mathrm{Ihm}$, aber auch Frau Kilian und ihren Mitarbeiterinnen und Mitarbeitern ist in besonderem Maße für eine äußerst gelungene Tagung zu danken, die allen Teilnehmern noch lange in Erinnerung bleiben wird.

Einschließlich Begleitung waren über 300 nach Halle gekommen. Mit den seit der letzten Tagung neu aufgenommenen zehn Kollegen zählt die Vereinigung mittlerweile (Stand: Oktober 1994) 380 Mitglieder. In der Mitgliederversammlung wurde der verstorbenen Mitglieder Heinrich Kipp, Hermann Soell und Friedrich-August Freiberr von der Heydte gedacht. Die Vereinigung wird ihnen ein ehrendes Andenken bewahren.

Der Rektor der Martin-Luther-Universität Halle-Wittenberg und der Oberbürgermeister der Stadt Halle empfingen die Teilnehmer am ersten Abend im Stadthaus am Marktplatz. An gleicher Stelle waren sie am zweiten Abend Gast der Landesregierung Sachsen-Anhalt. Zuvor hatte Otto Depenheuer in der Marktkirche ein Orgelkonzert besonderer Güte dargeboten. Der festliche Gesellschaftsabend nach Abschluß des wissenschaftlichen Programms eröffnete mit einer Revue im neuen Theater Einblicke in die "DDR der 50er Jahre" und gab anschließend unter den Klängen einer Big Band Gelegenheit zum Tanz. Der traditionelle Samstagausflug führte die Teilnehmer über Landsberg nach Wittenberg, wo das Luthermuseum, das Rathaus, die Schloßkirche und die CranachHöfe besichtigt werden konnten. Das von den Hallenser Gastgebern organisierte Begleitprogramm bot eine reiche Auswahl von Ausflügen in 
die nähere und weitere Umgebung. Dazu gehörten die Fahrt zum Kyffhäusergebirge und nach Bad Frankenhausen, der Besuch von Schloß Neuenburg und des Naumburger Doms, die Führung über den Stadtgottesacker und durch die Francke'schen Stiftungen, oder auch die Fahrt nach Dessau mit der Besichtigung des Bauhauses und der Ausflug nach Bad Lauchstädt zu den historischen Kuranlagen und dem Goethetheater; auch konnte Halle mit einer historischen Straßenbahn "entdeckt" und danach das Salinemuseum besucht werden.

Im Jahre 1995, vom 4. bis 7. Oktober, wird die Vereinigung ihre Jahrestagung zum dritten Mal, nach 1928 und 1958, in Wien abhalten. Für 1996 nahm die Mitgliederversammlung mit Dank die Einladung nach Dresden an, ebenso diejenige für 1997 nach Osnabrück. 